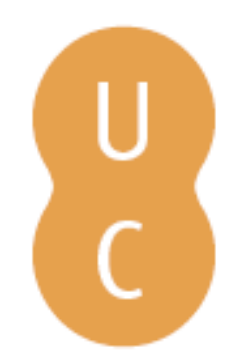

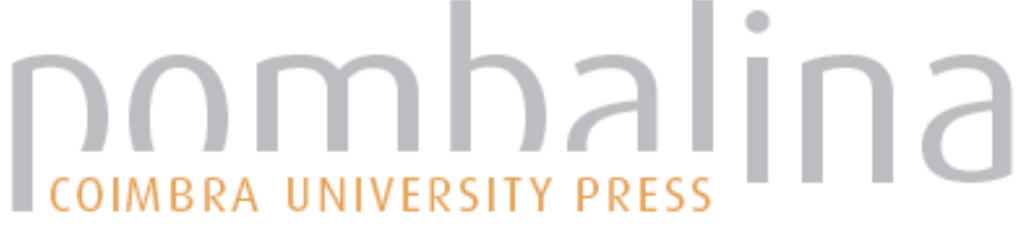

\section{Da exactidão das medidas à eficácia do processo de selecção}

Autor(es): $\quad$ Rodrigues, Nuno; Rebelo, Teresa

Publicado por: Imprensa da Universidade de Coimbra

URL

persistente: URI:http://hdl.handle.net/10316.2/31240

DOI: $\quad$ DOI:http://dx.doi.org/10.14195/978-989-26-0238-7_10

Accessed : $\quad$ 26-Apr-2023 12:33:59

A navegação consulta e descarregamento dos títulos inseridos nas Bibliotecas Digitais UC Digitalis, UC Pombalina e UC Impactum, pressupõem a aceitação plena e sem reservas dos Termos e Condições de Uso destas Bibliotecas Digitais, disponíveis em https://digitalis.uc.pt/pt-pt/termos.

Conforme exposto nos referidos Termos e Condições de Uso, o descarregamento de títulos de acesso restrito requer uma licença válida de autorização devendo o utilizador aceder ao(s) documento(s) a partir de um endereço de IP da instituição detentora da supramencionada licença.

Ao utilizador é apenas permitido o descarregamento para uso pessoal, pelo que o emprego do(s) título(s) descarregado(s) para outro fim, designadamente comercial, carece de autorização do respetivo autor ou editor da obra.

Na medida em que todas as obras da UC Digitalis se encontram protegidas pelo Código do Direito de Autor e Direitos Conexos e demais legislação aplicável, toda a cópia, parcial ou total, deste documento, nos casos em que é legalmente admitida, deverá conter ou fazer-se acompanhar por este aviso.

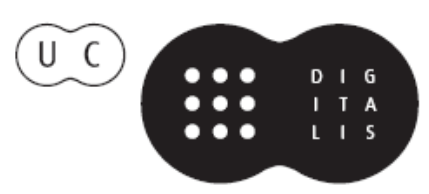



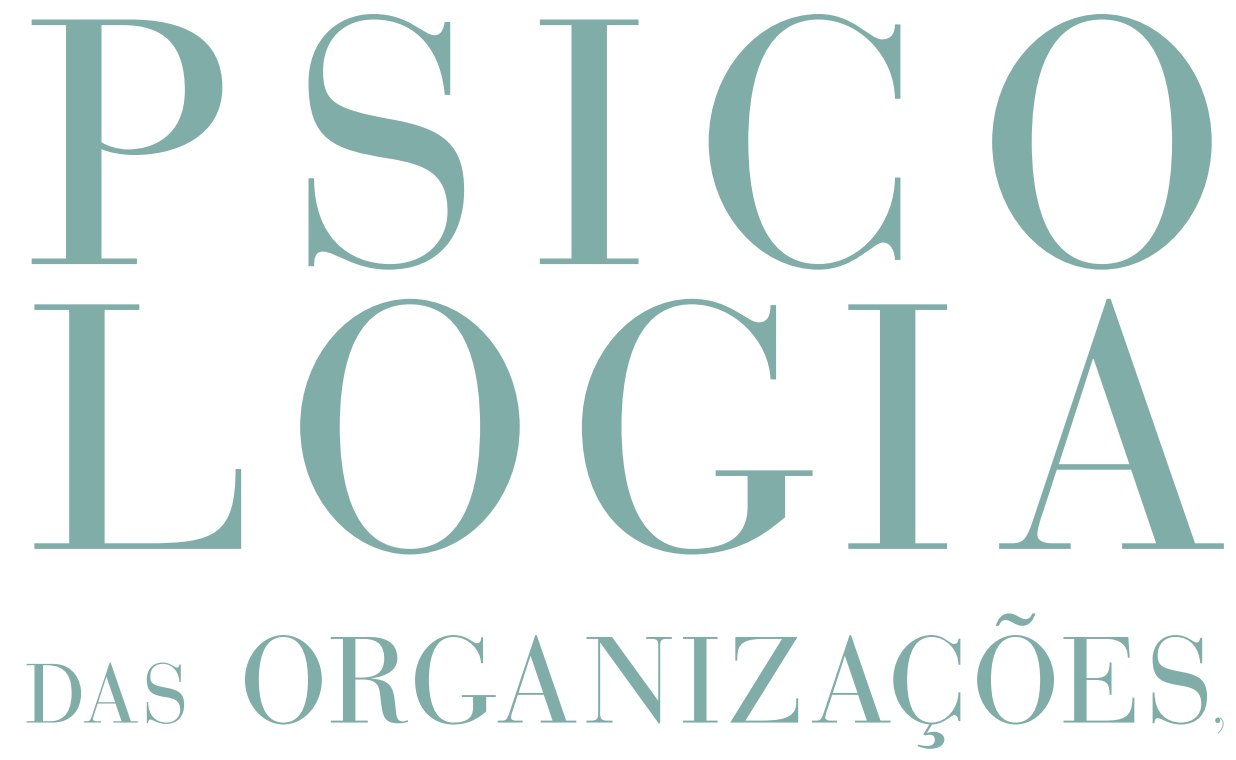

DO TRABALHO E DOS RECURSOS HUMANOS

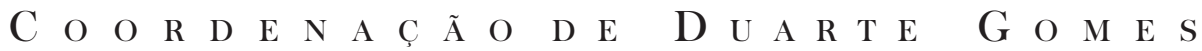

\section{Coimpra Companions}




\section{X}

DA EXACTIDÃO DAS MEDIDAS À EFICÁCIA Do Processo de SElECÇÃo

Nuno Rodrigues e Teresa Rebelo

UniversidADE DE COIMBRA 
(Página deixada propositadamente em branco) 


\section{INTRODUÇÃO}

Este capítulo partilha a temática do capítulo anterior munindo-se, todavia, de um conjunto de aspectos que se aglutinam nas questões concernentes à exactidão dos processos de selecção.

A secção inicial incide sobre noções fundamentais relacionadas com a fidelidade e validade dos métodos de selecção, conferindo-se especial destaque à análise do conceito de validade preditiva e do seu impacto na exactidão e, por consequência, na eficácia das práticas de selecção.

Na secção subsequente enunciam-se algumas notas acerca da definição, dimensões e mensuração do desempenho profissional e das implicações da utilização generalizada desta variável enquanto critério de validação dos instrumentos de medida/métodos utilizados na selecção de pessoas.

Por último, parte-se para a análise de alguns destes métodos, como os testes de aptidão cognitiva, os questionários de personalidade, os testes práticos de função e as entrevistas, com enfoque nas questões relacionadas com a frequência da sua utilização e com os coeficientes de validade preditiva (também designada validade relativa ao critério) que têm sido obtidos em estudos de inegável proeminência neste domínio.

Os principais tópicos que integram as secções deste capítulo serão revisitados no espaço final que lhe serve de conclusão, realçando-se alguns dos assuntos chave apresentados. 


\section{A EFICÁCIA do PROCESSO DE SELECÇÃo}

Como vimos, a selecção implica a tomada de decisões com o intuito de seleccionar o candidato cujas características individuais são passíveis de garantir níveis de desempenho satisfatórios no seio de uma determinada função e numa dada organização (Robertson \& Smith, 2001).

Se seguirmos este raciocínio é fácil depreendermos porque é que o foco de parte substancial da investigação no domínio da selecção tem incidido na identificação e mensuração das características individuais que provocam ou influenciam as diferenças no desempenho profissional das pessoas em contexto organizacional (Salgado et al., 2001; Smith, 1994).

Assim, para seleccionarmos, teremos de proceder à avaliação/medição de determinados atributos nas pessoas (aptidões, traços de personalidade, valores, atitudes, interesses, entre outros). A eficácia das decisões de selecção depende, entre outros aspectos, da exactidão das medidas /métodos aos quais recorremos.

As questões da medida são, de resto, fundamentais na investigação e prática da Psicologia das Organizações, do Trabalho e dos Recursos Humanos, pois possibilitam quantificar os atributos de variáveis de interesse com base em regras estandardizadas, claras e fáceis de aplicar, permitindo-nos assim descrever, tomar decisões, predizer e acrescentar inteligibilidade aos fenómenos que submetemos a estudo (Aguinis, Henle \& Ostroff, 2001; Stevens, 1968).

Desta forma, no contexto da selecção, as questões da medida relacionam-se, grosso modo, com a exactidão subjacente aos dados obtidos pelas ferramentas e métodos que utilizamos para decidir, noutras palavras, com a sua validade e fidelidade.

\subsection{FIDELIDADE}

A fidelidade prende-se com o grau em que uma determinada medida é consistente e estável ao longo do tempo. As questões da fidelidade visam determinar em que grau as diferenças encontradas nas pontuações se devem 
a alterações do atributo que estamos a medir e não a erros decorrentes de imperfeições do instrumento de medida (Decenzo \& Robbins, 2002).

As medidas das grandezas físicas são usualmente fidedignas porque a sua consistência é condição assumida à partida (por exemplo, uma fita métrica utilizada para medir as dimensões de um objecto). Tal não sucede com os métodos de selecção, à semelhança do que acontece com qualquer medida utilizada para medir aspectos do comportamento humano.

Os erros de medição, nestes casos, resultam predominantemente de mudanças nas pessoas quando respondem a uma determinada medida, como o cansaço, a ansiedade ou aspectos relacionados com as próprias condições de aplicação, que podem não ocorrer de uma forma sistemática ao longo das medições. Daí ser muito importante deter conhecimento acerca da fidelidade das medidas utilizadas em contexto de selecção.

Existem múltiplas formas de estimar o grau de fidelidade de uma medida, entre as quais encontramos a fidelidade teste-reteste, fidelidade inter-avaliadores e a consistência interna, noções que descreveremos seguidamente de forma sucinta.

A verificação de consistência entre diversas medições, resultantes da utilização de uma determinada medida em diferentes momentos, permite-nos concluir que essa medida possui fidelidade teste-reteste. Assim, se nos propomos medir repetidamente uma característica estável esperamos obter resultados similares nas diversas medições que formos realizando. Por exemplo, se aplicarmos uma escala de conscienciosidade a um determinado sujeito e verificarmos uma pontuação elevada neste traço, é expectável, caso a nossa escala seja fiável, que uma nova aplicação posterior (seis meses mais tarde) conduza a um resultado semelhante. Caso as pontuações oscilem de forma considerável isso significa que a nossa medida não é fiável, já que as flutuações não se devem muito provavelmente a alterações no atributo que estamos a medir mas a erros de medição (Kraiger \& Aguinis, 2001).

A fidelidade inter-avaliadores respeita ao grau de consistência das cotações obtidas pelos avaliadores com base na medida. Este método de estimação da fidelidade deverá ser utilizado quando uma medida depende de julgamentos subjectivos (ex: dados resultantes de observações, escalas de cotação de chefias). Trata-se de uma fonte de evidência que nos permite concluir acerca do 
grau em que as características dos avaliadores influenciam as cotações atribuídas a um determinado objecto ou pessoa num dado atributo (Kraiger \& Aguinis, 2001). Por exemplo, a situação na qual dois entrevistadores, apoiando-se num guião de entrevista comum, entrevistam um mesmo candidato e produzem pareceres distintos a propósito da sua contratação, sugere que a entrevista, no caso desta selecção, possui uma fidelidade reduzida.

Por fim, a consistência interna corresponde ao grau em que os itens que integram uma determinada medida se encontram relacionados entre si. Por exemplo, quando utilizamos uma escala constituída por múltiplos itens com o objectivo de medir o constructo extroversão, todos esses itens deverão pontuar de forma semelhante para que a medida seja fiável (Newell, 2005).

A fidelidade de uma medida expressa-se através de um coeficiente que representa a variância resultante de diferenças no atributo que está a ser medido.

De acordo com Nunnally (1978), se o objectivo da medida se prende com a execução de comparações individuais (como as medidas de selecção), o coeficiente de consistência interna deverá ser superior a .90 (o que raramente se verifica). No entanto, quando se tratam de objectivos de investigação, .70 representa um valor aceitável.

\subsection{VALIDADE}

O facto de uma determinada medida estar dotada de consistência ou fidelidade não constitui condição suficiente para que possamos garantir que a mesma é válida.

A validade remete para a utilidade das inferências que se podem efectuar utilizando as pontuações fornecidas por um instrumento de medida. Em rigor, o problema da validade consiste em determinar se a medida mede efectivamente o que deveria medir e se a mesma poderá ser utilizada para efectuar predições providas de exactidão (Aguinis et al., 2001).

Existem diversos tipos de evidência que devem ser recolhidos para determinar a validade de uma medida e que no domínio da selecção se revestem de particular relevância: validade relativa ao conteúdo, validade 
relativa ao constructo, e validade relativa ao critério (Aguinis et al., 2001; Binning \& Barret, 1989).

A validade relativa ao conteúdo concerne à adequação do conteúdo da medida ao atributo que visa medir. Por outros termos, se os itens ou questões que integram a medida constituem uma amostra representativa do conteúdo/das dimensões do atributo em consideração. Para que possamos estimar se uma determinada medida possui validade de conteúdo recorremos a pareceres de indivíduos que se incluem no grupo-alvo no qual pretendemos utilizar a medida, bem como a pareceres de peritos (ou experts) que possuem grande conhecimento acerca do atributo em causa.

Ao transpor este conceito para o contexto de selecção podemos afirmar que um teste construído para uma determinada função possui validade de conteúdo quando as questões ou tarefas que o constituem representam uma amostra representativa das tarefas que se incluem na função à qual o mesmo diz respeito (Decenzo \& Robbins, 2002).

Desta forma a construção de métodos dotados de validade de conteúdo encontra-se em clara dependência da qualidade da análise e descrição da função para a qual estamos a seleccionar.

Os testes que possuem validade de conteúdo reúnem geralmente um melhor grau de aceitação junto dos candidatos e relacionam de forma mais próxima os procedimentos de selecção com a função a que correspondem (Cook, 2004). As amostras de trabalho ou testes práticos de função (work sample tests) são um exemplo de um teste de selecção que pela sua similaridade física e psicológica com as tarefas nucleares da função à qual concerne o teste, quando correctamente construídas, tendem a evidenciar bons índices de validade de conteúdo.

A validade de constructo, por seu turno, assume também contornos importantes quando procuramos averiguar se a medida mede efectivamente o que julgamos que está a medir.

Os constructos são entidades abstractas não observáveis, de modo que para os estudarmos necessitamos de medidas que os operacionalizem.

Para concluirmos acerca da validade de constructo de uma determinada medida dever-se-á proceder à averiguação de três aspectos principais: 
a) especificar o domínio das manifestações observáveis relacionadas com o constructo; b) verificar em que grau as variáveis observáveis tendem a medir a mesmo constructo ou medem constructos diferentes; e c) investigar posteriormente e de forma controlada as diferenças individuais de modo a determinar o grau em que as medidas que foram utilizadas para medir o constructo produzem resultados congruentes e esperados pelas hipóteses teóricas que lhe dizem respeito (Nunnally, 1978). Em rigor, neste último passo, procede-se a uma análise das relações entre a medida e medidas de outros constructos, de forma a verificar se relações apresentam resultados semelhantes nas mesmas condições experimentais e se o sentido e a magnitude encontradas correspondem ao que seria previsível teoricamente.

A validade relativa ao critério ou validade preditiva possui particular relevância no domínio da selecção porque relaciona-se com o grau em que uma determinada medida poderá ser utilizada para efectuar predições e tomar decisões (Aguinis et al., 2001).

A determinação da validade preditiva de um método de selecção exige o estudo da correlação entre os resultados obtidos com base método de selecção em causa (preditor) e variáveis organizacionais importantes (critérios) como o desempenho profissional, o absentismo, turnover ou o êxito na formação (Cook, 2001; Smith \& Robertson, 2001).

O processo de validação do método de selecção permite-nos obter um coeficiente estatístico de correlação que se pode traduzir na capacidade de predição de um determinado preditor relativamente ao critério que se pretende estimar ${ }^{1}$ (ex: desempenho profissional) (Cook, 2004).

\footnotetext{
$1 \quad$ Existem dois tipos de designs que poderão ser utilizados na determinação da validade relativa a um critério de um método de selecção, os designs preditivos e os designs concorrentes. Os designs preditivos comportam a recolha dos resultados dos candidatos que participam num determinado sistema de selecção no teste ou método que pretendemos validar. As decisões de selecção não deverão ser apoiadas nos resultados deste mesmo teste durante o estudo de validação. As pontuações no critério ou seja a avaliação dos seus desempenhos, que geralmente é efectuada com base em escalas que são pontuadas pelas suas chefias, são recolhidas após a integração dos candidatos na organização (Aguinis, Henle, \& Ostroff, 2001). Os designs preditivos são pouco utilizados devido ao facto de implicarem um intervalo de tempo entre a obtenção dos resultados do preditor e do critério e de exigirem grandes amostras.

Tendo por base todos estes constrangimentos práticos, os esforços de investigação nesta área tendem a utilizar designs concorrentes, no âmbito dos quais as medidas no preditor e
} 
Os coeficientes de correlação poderão tomar valores situados entre -1 e 1 , sendo que a coeficientes mais elevados (mais próximos de 1 ou de -1) estão associadas maiores capacidades preditivas, permitindo-nos, assim, efectuar predições dotadas de maior precisão com base nos métodos em questão.

Estes coeficientes recebem usualmente a designação de coeficientes de validade preditiva e constituem uma característica importante na determinação da utilidade dos métodos de selecção².

O desempenho profissional individual corresponde à variável critério mais estudada na validação dos métodos (designados em linguagem psicométrica por preditores) comummente utilizados na selecção de pessoas, como são exemplos os testes de aptidões cognitivas, os questionários de personalidade, as worksamples, as entrevistas, entre outros.

Adoptando o princípio de que as acções de selecção visam escolher os candidatos mais adequados à função e à organização em termos de desempenho ulterior, então é fundamental que os métodos de selecção que utilizarmos discriminem entre os candidatos no que toca ao seu desempenho na função. Assim, os candidatos que pontuam de forma satisfatória num determinado método de selecção e cujos bons resultados conduzam à sua contratação deverão constituir-se em futuros colaboradores que produzirão níveis de desempenho satisfatórios.

O objectivo do método será sempre evitar seleccionar pessoas que são pontuadas como bons candidatos mas que se revelarem maus colaboradores posteriormente (falsos positivos) e vice-versa, ou seja, candidatos que obtêm maus resultados no método de selecção mas são colaboradores que atingem bons desempenhos (falsos negativos), como se explicita na Figura 1 (Newell, 2005).

no critério são recolhidas em simultaneidade, isto porque a amostra de validação é constituída por colaboradores da empresa e não por candidatos.

2 O cálculo da utilidade de um determinado método de selecção concerne à quantificação económica dos ganhos que advêm da sua utilização. Implica a consideração da validade preditiva do método, do custo inerente à sua aplicação e da variabilidade do desempenho na função (expressa em unidades económicas) (Brodgen, 1950; Ribeiro, 2000). 


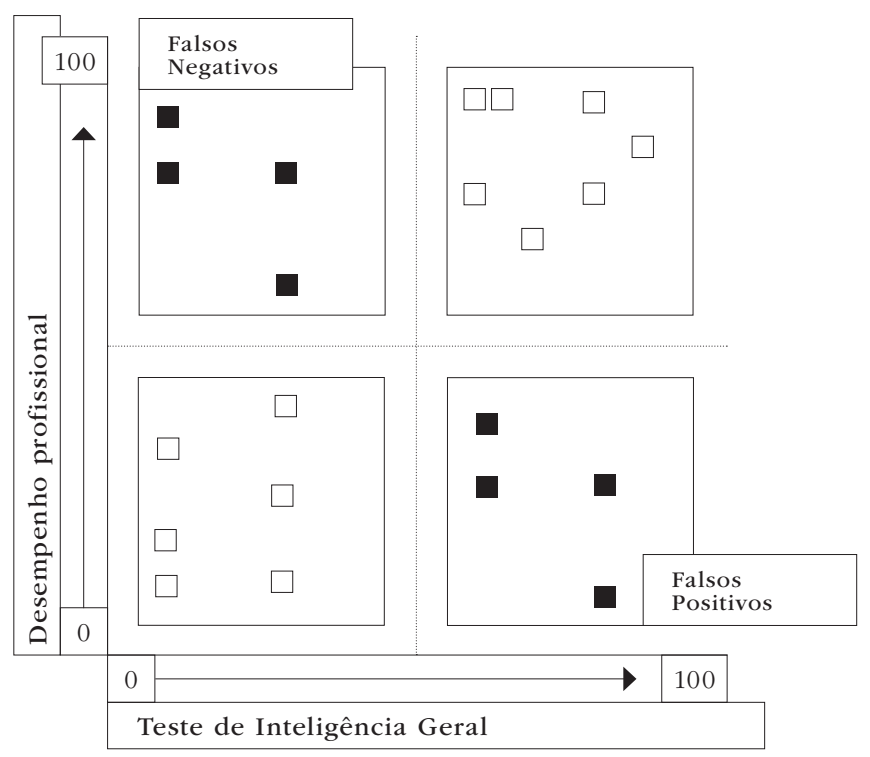

Figura 1 - Validade preditiva de um método de selecção

[Adaptado de Newell (2005)]

A não existência de uma relação significativa entre o método de selecção e o desempenho profissional indica-nos que o preditor não possui validade preditiva e, como tal, não nos permite seleccionar os candidatos com base no seu desempenho.

Um outro aspecto de grande importância na determinação da validade preditiva, além da medição dos preditores, diz respeito à medição do critério maioritariamente utilizado, o desempenho profissional. A sua natureza complexa levanta questões de difícil resolução na sua operacionalização, pois as dimensões que o constituem raramente são passíveis de quantificação objectiva.

\section{Em síntese:}

- Os procedimentos de selecção envolvem a medição de atributos nos indivíduos que correspondem a critérios de decisão (selecção), como aptidões, traços de personalidade, conhecimentos específicos; 
- A qualidade das decisões de selecção depende da exactidão das medidas através das quais acedemos às características em apreço. As questões da validade e fidelidade têm um papel central neste domínio;

- A fidelidade respeita à consistência e estabilidade das pontuações obtidas por uma determinada medida. Entre as formas de aferir a fidelidade encontra-se a fidelidade teste-reteste, o acordo inter-avaliadores e a consistência interna;

- A obtenção do índice de validade de uma medida concerne à determinação do grau em que a mesma mede o que tenciona medir, assim como à sua capacidade para realizar predições dotadas de exactidão;

- A validade de conteúdo, validade de constructo e validade preditiva (ou relativa ao critério) constituem formas distintas de evidência que poderão ser utilizadas na avaliação da validade de um instrumento de medida;

- A validade preditiva, em particular, detém particular interesse no domínio dos métodos de selecção porque permite retirar conclusões acerca da capacidade dos mesmos para efectuar predições em relação a um critério a partir do qual se pretende filtrar os candidatos (desempenho profissional, absentismo, turnover, entre outros).

\section{O CRITÉRIO “DESEMPENHO PROFISSIONAL INDIVIDUAL"}

Como verificámos, a validade preditiva de um determinado método toca à capacidade do mesmo em prever, com determinado nível de confiança, o critério, que geralmente corresponde à performance individual.

A optimização dos níveis de desempenho individual constitui, de resto, um dos principais vectores que norteiam as acções dos psicólogos nos contextos organizacionais (Viswesvaran, 2001). 
A investigação científica deste domínio tem procurado identificar que características individuais se encontram na origem das diferenças observadas no desempenho dos indivíduos.

O desempenho profissional individual pode definir-se como um conjunto de comportamentos ${ }^{3}$ que são relevantes para a concretização dos objectivos da função e da organização (Viswesvaran, 2001).

O desempenho profissional é um constructo abstracto, cuja mensuração encerra grande complexidade. Todavia, os estudos de validade preditiva dos métodos de selecção têm contribuído para a clarificação conceptual deste constructo, através do estudo das suas relações com variáveis preditoras (aptidão cognitiva geral, traços de personalidade), medidas através dos métodos de selecção (Guion, 1998).

É precisamente no nível relacionado com a medição deste critério que se encontram os maiores desafios quando se pretende estudar a validade preditiva de um determinado método de selecção.

Estes constrangimentos derivam, em grande parte, da dificuldade de conceber uma medida de desempenho profissional que seja simultaneamente válida, representativa e aceite por gestores e colaboradores (Arvey \& Murphy, 1998).

Trata-se de um problema resolúvel de forma relativamente simples nos casos em que o desempenho é susceptível de ser avaliado através de indícios objectivos, numa palavra, quando os resultados são passíveis de serem quantificados (sob a forma por exemplo, de registos organizacionais como o número de peças produzidas por um colaborador por hora, ou o volume de vendas efectuado por um comercial num dado período de tempo). Todavia, tal objectivação não é exequível na maioria das situações laborais, dificultando o estabelecimento de um acordo relativamente pacífico acerca do que significa desempenho efectivo para gestores, trabalhadores e supervisores (Cook, 2004).

Apesar das medidas objectivas permitirem contornar algumas destas dificuldades, podem originar problemas de outra natureza na medição, pois

\footnotetext{
A utilização do termo comportamentos ao invés de resultados pretende excluir da definição de desempenho individual todos os aspectos ou factores que não estão sob o controlo do indivíduo (Campbell, 1990).
} 
revelam-se por vezes incompletas (deficientes), irrelevantes ou contaminadas por factores que não pertencem ao construto de produtividade individual. A Figura 2 apresenta uma esquematização destes aspectos (Robertson \& Smith, 2001).

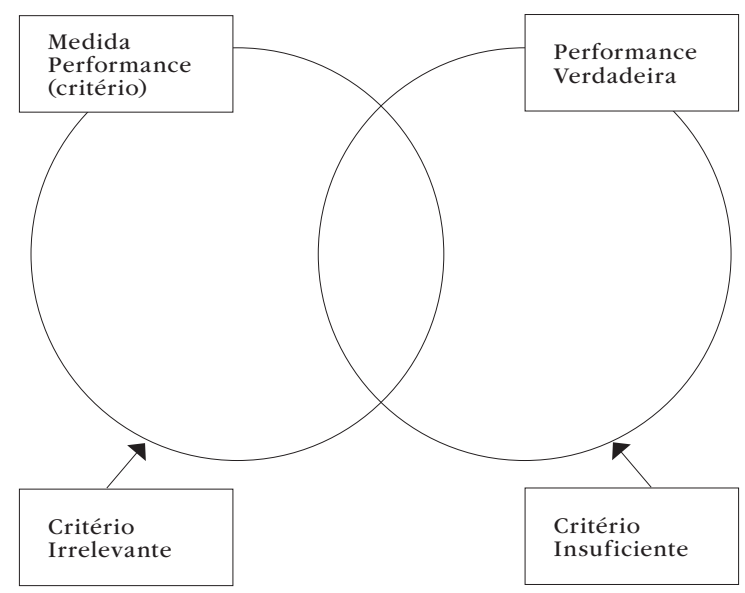

Figura 2 - Representação esquemática da variância verdadeira do desempenho profissional e por justaposição com a variância do critério (medida de desempenho) [Fonte: Cook (2004)].

Não obstante a existência de vários métodos de avaliação da performance individual (registos organizacionais e avaliações subjectivas), as escalas do supervisor/chefia directa constituem a medida mais utilizada no âmbito dos estudos da validade relativa ao critério (Cook, 2004).

A forma mais frequente deste tipo de escalas subjectivas integra uma série de dimensões com níveis diferentes e gradativos de desempenho que são preenchidas pelo supervisor directo de um dado colaborador. Este deverá assinalar o nível que melhor representa o desempenho do trabalhador em causa (Cook, 2004).

Porém, as escalas de avaliação de desempenho sofrem com frequência de falta de fiabilidade e de excesso de subjectividade.

Todas estas limitações constituem verdadeiras fontes de erro que obscurecem e dificultam a interpretação das dimensões que estão subjacentes ao constructo de desempenho profissional. 
Assim, múltiplos autores têm procurado analisar as manifestações de desempenho das pessoas, como comportamentos e atitudes, com a pretensão de compreender e explicar as dimensões que lhe estão subjacentes (Viswesvaran \& Ones, 2000). A derivação das facetas ou dimensões de desempenho é indispensável na viabilização de análises que visam determinar o poder preditivo dos vários métodos de selecção em cada dimensão. Assim, um questionário de personalidade que avalie o traço amabilidade poderá não possuir validade preditiva na dimensão de desempenho de tarefa mas é susceptível de constituir um preditor válido dos comportamentos individuais direccionados para a dimensão de desempenho contextual.

Hunt (1996), com base na análise de funções pertencentes ao sector retalhista, identificou nove dimensões de desempenho (retail sector): adesão às regras, capacidade empreendedora, flexibilidade de horários, assiduidade, (off-task behaviour) comportamentos extra-papel, obediência, inexistência de comportamentos de roubo e abuso de substâncias tóxicas. À semelhança deste autor, múltiplos investigadores têm trabalhado sobre estas questões e, desta forma, têm contribuído para o surgimento de taxonomias de desempenho caracterizadas por grande variabilidade. Como tal, ainda se afigura longo o caminho para a consecução de um grau satisfatório de consenso a propósito desta matéria entre os autores do domínio (Robertson \& Smith, 2001).

Contudo, apesar da ausência de unanimidade acerca de tais dimensões, verifica-se um reconhecimento relativamente consensual de que este constructo possui uma natureza multidimensional (Campbell, 1990; Conway, 1996; Murphy \& Shiarella, 1997; Rebelo, 2006).

Os investigadores discordam, de forma cada vez mais convicta, da concepção que reduz o desempenho de um determinado colaborador à sua performance nas tarefas técnicas que integram a função.

Borman e Motowidlo (1993) sustentam que a produtividade individual se pode descrever com base nas dimensões-macro de desempenho de tarefa e desempenho contextual, nas quais se podem agrupar as múltiplas sub-dimensões de performance presentes nas diversas taxonomias existentes.

Motowidlo e Van Scotter (1994) analisaram empiricamente esta distinção entre desempenho de tarefa e desempenho contextual, recorrendo às escalas 
de avaliação de desempenho de 400 operadores de mecânica. Os resultados globais desta análise apontaram para a existência de duas dimensões independentes que contribuem de forma singular para a performance global.

Estas dimensões, paralelas aos subsistemas técnico e social que formam a organização, parecem ser transversais a todas funções ${ }^{4}$ (Motowidlo, Borman, \& Van Scotter, 1997; Viswesvaran, 2001).

A primeira dimensão assume a designação de desempenho de tarefa e respeita aos comportamentos relacionados com a execução dos processos e actividades técnicas da função (Borman \& Motowidlo, 1993).

Alguns estudos têm sustentado a existência de relações mais robustas da dimensão supracitada e diferenças individuais ao nível de preditores como as aptidões cognitivas, a experiência profissional e o conhecimento específico de função (Borman \& Motowidlo, 1993; Hattrup \& O'Connel, 1998).

A segunda dimensão assume a designação de desempenho contextual ${ }^{5}$ e relaciona-se com um conjunto de comportamentos extra-papel que contribuem para a criação de um ambiente social e psicológico facilitador da concretização dos objectivos organizacionais.

Esta dimensão inclui comportamentos como persistir com entusiasmo e esforço, voluntariar-se para a consecução de deveres que não estão formalmente consagrados no quadro da função; aprovar e suportar os objectivos de grupo e organizacionais, assim como colaborar com os colegas de trabalho (Borman \& Motowidlo, 1997).

Os comportamentos que se aglutinam na dimensão de desempenho contextual são susceptíveis de facilitar a comunicação e actuarem como redutores de tensão e de respostas emocionais disruptivas, detendo um papel crítico no êxito dos grupos ou equipas de trabalho, pois concretizam o contexto social e motivacional necessário à actividade profissional (Morgenson, Reider, \& Campion, 2005).

4 No entanto, Conway (1999) verificou, com base em procedimentos de análise factorial que esta distinção se torna menos saliente no caso das funções de gestão.

5 Este construto de desempenho contextual apresenta grande similaridade com os conceitos de cidadania organizacional e de espontaneidade organizacional (Arvey \& Murphy, 1998). 
A conscienciosidade, a motivação e o estilo de interacção interpessoal constituem variáveis que têm surgido em diversos estudos, com relações assinaláveis com o desempenho contextual (Borman \& Motowidlo, 1997).

Apesar de se postular uma relação de teor mais robusto entre a conscienciosidade e o desempenho contextual, Motowidlo, Borman e Van Scotter (1997) sustentam que este factor poderá também produzir efeitos no desempenho de tarefa, através do seu impacto nos hábitos de realização das tarefas da função. De igual modo, as aptidões cognitivas podem também afectar a performance contextual, ainda que de forma menos expressiva, através dos seus efeitos nas auto-percepções atinentes ao papel profissional.

Uma terceira dimensão de desempenho que tem integrado os estudos de validade preditiva refere-se aos comportamentos contra-produtivos e corresponde a uma definição pela negativa do desempenho. Trata-se de um conjunto de comportamentos que violam as normas organizacionais e deterioram o ambiente social, actuando como agentes corrosivos à concretização dos objectivos da organização (Mount, Ilies, \& Johnson, 2006). É importante realçar que estes comportamentos variam na sua natureza e intensidade, podendo manifestar-se sob a forma de indolência, desperdício propositado/imponderado de recursos, absentismo, abuso de substâncias tóxicas ou roubo (Dilchert, Ones, Davis, \& Rostow, 2007).

A conscienciosidade, a amabilidade, e a estabilidade emocional, tal como outras variáveis que aludem a mais do que um traço de personalidade, como o auto-controlo ou a integridade, têm revelado poder preditivo em relação a este critério (Dilchert et al., 2007).

\section{Em síntese:}

- O desempenho profissional individual constitui o critério mais estudado e que tem registado maior utilização na validação dos métodos de selecção;

- Diversos autores operacionalizam o desempenho profissional como um conjunto de comportamentos que contribuem para a concretização dos 
objectivos adjacentes a uma determinada função num dado contexto organizacional;

- A sua mensuração encerra questões de difícil resolução devido ao seu carácter abstracto e à dificuldade inerente à sua objectivação. A utilização de medidas subjectivas, com frequência escalas cujo preenchimento é realizado pelas chefias directas, surge na base da dificuldade em quantificar o desempenho, para além de, por vezes, sofrem de problemas de fidelidade ou consistência;

- Alguns autores sustentam que os comportamentos relacionados com o desempenho laboral são passíveis de se incluírem nas dimensões chave de desempenho de tarefa, desempenho contextual e comportamentos contraprodutivos.

\section{As ferramentas de decisão: Os métodos de Selecção - Algumas} NOTAS EM TORNO DA SUA VALIDADE PREDITIVA DO DESEMPENHO PROFISSIONAL

Nesta secção iremos presidir à apresentação e discussão de algumas questões de manifesta preponderância no domínio de investigação dos métodos de selecção. Partiremos, assim, para a descrição das características dos diferentes métodos que tem conhecido maior utilização em contextos de selecção e que têm originado uma produção científica substancial relacionada, mormente, com as questões em torno da sua validade.

A investigação produzida no domínio do recrutamento e selecção com início na década de 70 e 80 tem demonstrado que os coeficientes de validade preditiva ${ }^{6}$ respeitantes aos métodos amplamente utilizados na selecção de pessoas, como os testes de aptidões cognitivas, os questionários de

6 Tal como já foi referido, o coeficiente de validade preditiva de um determinado método de selecção corresponde ao coeficiente de correlação que se estabelece entre os resultados obtidos no método em causa e os resultados da variável critério considerada. 
personalidade, as entrevistas, entre outros, possuem magnitudes distintas consoante a faceta de desempenho em causa.

\subsection{TESTES DE APTIDÕES}

De entre os múltiplos métodos de selecção, os testes de aptidão cognitiva construíram-se, desde a $1^{\mathrm{a}}$ guerra mundial, numa prática extremamente comum no âmbito dos processos de recrutamento e selecção em todo o mundo (Salgado et al., 2001).

No contexto Europeu, a taxa de utilização dos testes de aptidões é superior em países como a Bélgica, Inglaterra, Holanda e Portugal, comparativamente aos Estados Unidos da América (Salgado \& Anderson, 2002).

O estudo da relação entre estes testes e os critérios de desempenho profissional e o êxito na formação ocupa um lugar central na literatura sobre selecção de pessoas (Ree et al., 2001).

Diversas investigações têm sido realizadas com o propósito de estudar a capacidade preditiva da aptidão cognitiva geral, assim como das aptidões cognitivas mais específicas (aptidão numérica, verbal, espacial, entre outras).

A aptidão cognitiva geral, designada também como inteligência geral, remonta ao constructo de factor $g$, decorrente das teorias unitárias de inteligência de Spearman (1927) (Carreta \& Ree, 2000).

De acordo com Gottfredson (2002), o factor $g$ respeita à competência para lidar com a complexidade e de aprender com rapidez e eficiência noções complexas, evitando erros cognitivos. Numa palavra, $g$ reifica a habilidade de processar informação de índole variada.

Um conjunto de estudos primários desenvolvidos ao longo de um século tem conferido à aptidão cognitiva geral ou inteligência geral o estatuto de preditor válido do desempenho profissional e do êxito na formação (Salgado et al., 2001).

Os resultados destes movimentos de investigação possibilitaram a execução subsequente de inúmeras investigações de meta-análise iniciadas por volta da década de setenta nos EUA (Levine, Spector, Menon, Narayon, \& Cannon-Bowers, 1996; Hunter \& Hunter, 1984; Pearlman, Schmidt, \& Hunter, 
1980) e mais recentemente na Europa (Bertua, Anderson, \& Salgado, 2005; Salgado \& Anderson, 2002; Salgado, Anderson, Moscoso, Bertua, De Fruyt, $\&$, Rolland, 2003). Estes estudos permitiram a obtenção de estimativas providas de maior exactidão acerca dos coeficientes de validade preditiva relativos aos diversos métodos de selecção, através da remoção de fontes de erro dos estudos primários (falta de fiabilidade das medidas, amostras demasiado reduzidas) (Hunter \& Schmidt, 1990).

Hunter e Hunter (1984) conduziram a primeira grande meta-análise sobre estas questões. Este estudo incidiu sobre 515 estudos $(N=38620)$ nos quais se mediu a aptidão cognitiva geral através da bateria GATB (General Aptitude Test Batery). O coeficiente médio de validade preditiva obtido (corrigido para a falta de fiabilidade do critério e para a restrição da amplitude ${ }^{7}$ ) assumiu o valor de .45 para o desempenho profissional, medido com base nas escalas de avaliação do desempenho, e de .54 quando a variável critério correspondia ao êxito na formação.

O carácter convergente dos resultados deste estudo e de outras meta-análises posteriores realizadas em contexto norte-americano (Levine, Spector, Menon, Narayon, \& Cannon-Bowers, 1996; Pearlman, Schmidt, \& Hunter, 1980) conferiu à aptidão cognitiva geral o estatuto do melhor preditor individual do desempenho profissional (com coeficientes em torno de .55) e do sucesso na formação (coeficientes à volta de .60).

No que respeita ao contexto europeu, Salgado, Anderson, Moscoso, Bertua e Fruyt (2003) realizaram uma investigação relevante de meta-análise dotada de considerável abrangência. Esta investigação baseou-se em estudos de dez países da comunidade europeia e permitiu obter um coeficiente de validade corrigido (para a falta de fiabilidade das medidas e para a restrição de amplitude) de .62 para as escalas de avaliação de desempenho. Trata-se de um coeficiente com uma magnitude sem precedentes no domínio dos estudos de meta-análise dedicados a estas questões. No que diz respeito

\footnotetext{
A restrição de amplitude constitui um factor de erro que decorre do facto apenas alguns candidatos serem escolhidos para integrar a organização durante a fase de selecção. Assim, o estudo da relação entre preditor(es) e critério(s) irá incidir apenas sobre os candidatos seleccionados, restringindo-se a amplitude no(s) preditor(es), na medida em que se perde a variabilidade que resultaria dos candidatos que foram excluídos inicialmente (Cook, 2004).
} 
ao êxito da formação, o coeficiente observado tomou o valor de .54, tratando-se, como se pode constatar, de um coeficiente relativamente próximo do que resultou da investigação de Hunter e Hunter (1984).

Esta multiplicidade de estudos, realizados em países diversos e pertencentes a diferentes continentes, permitiu concluir que a validade preditiva da aptidão cognitiva geral se generaliza a diferentes contextos organizacionais, culturas, concepções de desempenho, sistemas económicos e legislações laborais distintas (Salgado et al., 2003).

A evidência empírica resultante destes estudos suporta, de igual modo, a hipótese de que a validade dos testes desta natureza se generaliza a diversas funções, contextos e amostras organizacionais (Salgado et al., 2001; Schmidt, 2002).

Contudo, a complexidade das funções em análise tem emergido em múltiplas pesquisas como um moderador importante da validade de $g$.

De facto, a complexidade de uma determinada função relaciona-se de forma íntima com as exigências de processamento, manipulação e transmissão de informação que a mesma comporta (Gottfredson, 2002).

Hunter e Hunter (1984) concluíram que a um aumento de complexidade da função corresponde um aumento da validade dos testes de aptidão cognitiva. Assim, os coeficientes encontrados por estes autores oscilavam de .50 até .65 para funções providas de maior complexidade, no caso do critério êxito na formação. No que toca às escalas de avaliação de desempenho, os coeficientes variam de .58 para funções altamente complexas até .23 para funções de complexidade menor.

Hunter (1983) estudou as relações entre a aptidão cognitiva geral e a aquisição do conhecimento específico da função e concluiu que a aptidão cognitiva geral constitui um antecedente directo do conhecimento específico da função, o qual contribui, por sua vez, para o desempenho profissional. Dito de outra forma, estes resultados indicaram que a aptidão cognitiva contribui para o desempenho através dos seus efeitos directos na aquisição do conhecimento e na capacidade de desenvolver as competências requeridas.

Contudo, apesar das vantagens da aptidão cognitiva geral que decorrem da sua validade preditiva ímpar para os critérios que têm sido alvo de estudo, este preditor reúne algumas desvantagens particularmente relevantes, 
enquanto ferramenta de selecção, que se relacionam com as questões do impacto adverso (Avis, Kudish, \& Fortunato; 2002; Hunter \& Hunter, 1984; Outtz, 2002; Smith, 1994). Este problema decorre das diferenças de pontuação encontradas nos testes de aptidão cognitiva geral entre diversos grupos sociais $^{8}$. Estas diferenças apresentam, com frequência, uma magnitude significativa ${ }^{9}$ e acabam por estar na génese de taxas de contratação desiguais entre grupos, quando os resultados nos testes de aptidão cognitiva geral constituem um critério de selecção. A natureza destas questões levanta sérias implicações legais, que respeitam sobretudo à promoção de iguais oportunidades de emprego, independentemente do grupo social em causa (Outtz, 2002).

\subsection{APTIDÕes CogNitivas EsPECÍficAS}

A investigação neste domínio têm incidido, de igual forma, no estudo da validade preditiva de aptidões cognitivas mais específicas comparativamente à aptidão cognitiva geral. Trata-se de constructos teóricos que decorreram das teorias pluralistas da inteligência que advogavam que a actividade mental era irredutível a um único factor, constituindo-se por várias aptidões ou factores relativamente independentes (Ree et al., 2001).

No início da última década, os investigadores postulavam que as aptidões específicas (aptidão verbal, numérica, perceptiva, espacial, entre outras) possibilitariam a predição do desempenho laboral de uma forma mais auspiciosa e promissora do que uma medida unitária de aptidão cognitiva geral (Schmidt, 2002). As teorias das múltiplas aptidões assentavam na premissa de que a funções distintas estariam subjacentes perfis de aptidões específicos e diferenciados.

\footnotetext{
8 Por exemplo, Hunter e Hunter (1984) verificaram que os afro-americanos se situavam um desvio padrão abaixo da média dos indivíduos americanos de raça branca nos testes de aptidão cognitiva.

9 No caso dos Hispânicos e Americanos os resultados variavam de .45 para .58 , respectivamente (Schmidt, Clause, \& Pulakos, 1996). Em relação às diferenças entre homens e mulheres a performance das mulheres deteve um carácter inferior à dos homens, no entanto, o tamanho do efeito encontrado é reduzido (.09).
} 
Assim, seria expectável que a aptidão cognitiva geral se constituísse num determinante necessário mas distal, enquanto que as aptidões específicas possuiriam o estatuto de determinantes proximais e, por consequência, seriam susceptíveis de se constituírem preditores mais robustos que $g$ (Reeve \& Hakel, 2002)

Apesar da plausibilidade desta hipótese, os resultados de diversas investigações e de estudos de meta-análise não apontaram no sentido do seu suporte empírico (Hunter \& Hunter, 1984; Pearlman, Schmidt \&, Hunter, 1980). Por outro lado, Ree et al. (2001) demonstraram que as aptidões específicas não oferecem validade adicional ao factor $g$ para os critérios do desempenho laboral e do êxito na formação. O aumento de validade preditiva decorrente da adição das aptidões cognitivas a $g$ situou-se na ordem de .02 para 89 estudos, cujo critério considerado respeitou ao êxito na formação. Num outro estudo, realizado por Olea e Ree (1994) a validade adicional das aptidões específicas em relação a $g$ foi de .08 e de .02 para o desempenho profissional na função de piloto e de operacionais da marinha, respectivamente.

Hunter e Hunter (1984) e Hartigan e Wigdor (1989) estudaram a validade da aptidão perceptiva e concluíram que, em termos genéricos, esta não suplantava a validade inerente à aptidão cognitiva geral. Neste estudo, a validade da aptidão cognitiva geral variava de .23 a .58 , dependendo da complexidade da função, quando o critério respeitava ao desempenho profissional, e de .50 a .65 para o sucesso na formação. No caso particular da aptidão perceptiva, os coeficientes oscilavam de .24 a .52 para o desempenho e de .26 até .53 para o sucesso na formação.

Como podemos constatar, a investigação tem permitido concluir que as aptidões específicas facultam um acréscimo muito pouco expressivo à validade preditiva da aptidão cognitiva geral (Carreta \& Ree, 2000).

No entanto, Bertua, Anderson e Salgado (2005), baseando-se em metodologias de meta-análise, concluíram que a validade da aptidão perceptiva igualava ou superava a validade da aptidão geral consoante o critério em análise. Assim, quando o critério considerado respeitava ao desempenho profissional, as validades variavam de .50 para a aptidão perceptiva e de .48 para a aptidão cognitiva geral. No caso do critério êxito na formação, 
a aptidão perceptiva e a aptidão cognitiva geral demonstraram um coeficiente semelhante, na ordem de .50. Contudo, os autores alertaram para o facto dos testes de aptidão perceptiva se terem revelado saturados em $g$, não se tratando, por conseguinte, de uma medida de natureza completamente distinta da aptidão cognitiva geral.

Diversos autores advogam, todavia, que a magnitude reduzida dos coeficientes de validade das aptidões específicas poderá decorrer do facto das investigações se circunscreverem aos critérios de desempenho e êxito na formação, incidirem num conjunto limitado de funções profissionais, e serem baseadas em amostras mais reduzidas, comparativamente às que têm sido utilizadas nos estudos da validade do factor geral (Bertua et al., 2005; Viswesvaran \& Ones, 2002)

Porém, o uso de aptidões específicas nos sistemas de selecção pode reduzir, segundo alguns autores, as diferenças entre grupos e suscitar reacções mais positivas junto dos candidatos, devido à sua maior validade facial (Ree et al., 2001; Viswesvaran \& Ones, 2002).

\subsection{VARIÁVEIS E MEDIDAS de PERSONALIDADE}

A utilização de medidas de personalidade na selecção de pessoas constitui um assunto que se encontra actualmente em debate aceso por parte dos múltiplos autores que se têm interessado por este domínio. A controvérsia e a divergência são, de resto, características que marcam transversalmente o estudo da validade preditiva das medidas de personalidade.

Nas décadas de 60 e 70, com excepção dos trabalhos de Ghiselli (1966), percepcionava-se a utilidade das variáveis de personalidade na predição do desempenho profissional com grande pessimismo (Guion \& Gottier, 1965; Salgado et al., 2001). A validade preditiva da personalidade para o critério em apreço revelava-se extremamente reduzida (Schmidt, Gooding, Noe, \& Kirsh, 1984). Por outro lado, a ausência de uma taxonomia compreensiva acerca da estrutura da personalidade inviabilizava uma classificação uniforme dos múltiplos traços presentes na literatura, impossibilitando que a investigação se revestisse de um carácter mais preciso e coerente. 
Diversos investigadores, no período precedente à década de 90, sustentavam que, em última análise, a personalidade não se relacionava com a performance profissional e, quando tal se verificava, a magnitude da associação revelava-se quase ínfima revelando-se, portanto, negligenciável (Hunter \& Hunter, 1984; Schmidt et al., 1984).

No entanto, a emergência da taxonomia big five, ao permitir a redução de um conjunto enorme de traços de personalidade a número menor de factores dotado de defensibilidade e congruência, proporcionou aos investigadores um quadro de referência sistematizador e organizador dos múltiplos estudos que se incluem neste domínio (Mount, Barrick \& Stewart, 1998).

Assim, as primeiras investigações de meta-análise efectuadas nesta área (Barrick \& Mount, 1991; Hough, 1992; Robertson \& Kinder, 1993) utilizaram esta taxonomia para organizar as escalas resultantes dos diversos inventários de personalidade, acrescentado assim maior rigor aos coeficientes obtidos.

Barrick e Mount (1991), através da metodologia de meta-análise, calcularam as validades preditivas dos cinco factores de personalidade nos critérios de proficiência profissional e êxito na formação. Esta investigação deu origem ao artigo científico mais citado dos anos 90 da revista "Personnel Psychology" (Mount \& Barrick, 1998). Em termos de resultados, os coeficientes corrigidos obtidos no âmbito deste estudo foram de .10 para a extroversão, .07 para o neuroticismo (também designado como estabilidade emocional), .06 para amabilidade, .23 para a conscienciosidade e - .03 para abertura à experiência.

Salgado (1997) efectuou uma outra meta-análise relevante com estudos europeus, obtendo coeficientes relativos ao critério desempenho laboral, que após correcção, assumiram o valor de .19 para a estabilidade emocional e de .25 para a conscienciosidade. Este mesmo autor, em 1998, reportou que a conscienciosidade se revestia de validade adicional relativamente à aptidão cognitiva geral. Os resultados obtidos neste último estudo indicaram que a conscienciosidade incrementava a variância explicada pela aptidão cognitiva geral em 12\%, aumentando a variância explicada pela estabilidade emocional em 7\%, considerando como critério, em ambos os casos, o desempenho profissional globalmente considerado, para funções pertencentes a contextos civis. 
Hurtz e Donovan (2000) baseando-se, de igual modo, em procedimentos de meta-análise concluíram que a personalidade se relacionava com o desempenho laboral, sendo que a magnitude dessa associação atingia o valor de .22 (coeficiente médio corrigido).

Ghiselli (1966), apesar de não ter especificado a taxonomia utilizada na organização dos estudos que analisou, encontrou um coeficiente médio não corrigido de .24 nas funções investigadas. Schmidt et al. (1984), sem a utilização de qualquer taxonomia, encontraram um coeficiente corrigido de .21 para a predição das escalas de avaliação de desempenho.

Estes resultados relativamente díspares sugerem, segundo Hough e Ones (2001), que a taxonomia utilizada, quer para os preditores, quer para as variáveis critério, se constitui num moderador importante das validades obtidas para as variáveis de personalidade. Por outro lado, a falta de validade convergente verificada entre as medidas utilizadas para medir o mesmo factor, os problemas relacionados com a respectiva validade de constructo e a não introdução de fórmulas psicométricas para refinar as estimativas dos coeficientes de validade podem ter afectado a exactidão dos coeficientes obtidos nas meta-análises. Acrescente-se também que, de acordo com Salgado (2003), os primeiros estudos de meta-análise desde 1991 (Barrick \& Mount, 1991; Hough, 1992; Robertson \& Kinder, 1993) podem ter introduzido erros artefactuais na estimação dos coeficientes de validade para as variáveis de personalidade, que podem ajudar a explicar a disparidade dos resultados obtidos nas investigações. A génese possível destes erros poderá residir no facto dos questionários de personalidade utilizados nos estudos que integraram as amostras das meta-análises não terem sido desenvolvidos no âmbito da taxonomia big five. Desta forma, Salgado (2003) conduziu uma investigação de meta-análise com base em estudos de validade europeus e americanos que utilizaram questionários big five e outros questionários que não se baseiam nesta taxonomia. Os resultados obtidos para a conscienciosidade foram de .28 para os questionários big five e de .18 para os restantes questionários. No caso da estabilidade emocional, a variação assumiu os valores de .16 até .05, não se verificando diferenças assinaláveis nas restantes dimensões.

A proliferação da investigação derivada deste novo interesse nas variáveis de personalidade e, em particular, a condução dos referidos estudos de 
meta-análise permitiu concluir que, de entre os traços de personalidade, a conscienciosidade $^{10}$ é o factor que se reveste de maior preponderância na predição do desempenho profissional (com coeficientes em torno de .20) em várias funções e contextos organizacionais (Hurtz \& Donovan, 2000; Mount \& Barrick, 1998; Ones, Viswesvaran, \& Schmidt, 1993; Salgado, 1997).

De realçar ainda que alguns autores, como Hough (1992) e Paunonem (1998), defendem que caso a investigação se centre exclusivamente na análise da validade preditiva das medidas globais da personalidade, pode negligenciar aspectos e facetas mais específicas, detentoras de um papel importante na compreensão das causas que estão na base das diferenças individuais no desempenho imputáveis à personalidade. No mesmo sentido, Hough (1992) e Mount e Barrick (1995) sustentam que a conscienciosidade deve ser dividida nos subfactores de realização (achievement) e confiabilidade (dependability). O subfactor realização respeita, grosso modo, à capacidade para trabalhar intensamente e cumprir metas. A confiabilidade, por seu turno, aglomera aspectos de um tonús mais interpessoal e que concernem a características relacionadas com a responsabilidade e com o cumprimento do dever.

Por seu turno, Costa e MacCrae (1998, cit in Lima, 1997) conceptualizam as facetas da conscienciosidade como aspectos passíveis de se agruparem em dois grupos distintos, o grupo proactivo e o grupo inibidor. Em consonância com estes autores, as facetas realização e obediência constituem aspectos proactivos, enquanto que as facetas ordem e auto-controlo constituem aspectos inibidores (Roberts, Chernysshenko, Stark, \& Goldberg, 2005).

Como podemos constatar, a investigação empírica realizada com as facetas de personalidade possui ainda um carácter relativamente incipiente, no entanto, diversos autores têm movido esforços na identificação dos traços nucleares da conscienciosidade. O resultado destes esforços tem permitido conceptualizar este factor com base em quatro facetas principais: realização, ordem, prudência e confiabilidade (Hogan \& Ones, 1997; Saucier \& Ostendorf,

10 Para Costa e MacCrae (1992, cit in Lima, 1997) a conscienciosidade concerne ao grau de organização, persistência e motivação pelo comportamento orientado para um objectivo. 
1999, cit in Dudley et al., 2006). A faceta realização reflecte a orientação do sujeito para o empenho, competência e sucesso no trabalho, e para a adopção de elevados níveis de performance na prossecução dos objectivos profissionais (Costa e MacCrae, 1992, cit in Lima, 1997). A faceta confiabilidade reflecte a tendência da pessoa para ser responsável, auto-disciplinada, fiável, de confiança, e respeitadora das regras e da autoridade (Hough, 1992). A faceta ordem, por sua vez, relaciona-se com tendência do sujeito para estruturar o seu ambiente de trabalho e enveredar por padrões de organização e orientação para os detalhes e para o comportamento metódico (Hough \& Ones, 2001). A faceta prudência, por fim, remete para a ponderação dos riscos inerentes a um dado curso de acção na fase que precede a sua execução, englobando um conjunto de aspectos diametralmente opostos à impulsividade e a não ponderação das consequências e riscos decorrentes das próprias acções (Hough \& Ones, 2001).

No que respeita à validade preditiva das facetas, os autores concluíram que estas podem possuir validade preditiva superior à que é detida pela conscienciosidade. Todavia, esse acréscimo de capacidade preditiva decorrente da consideração das facetas depende do critério e da função em causa.

Um outro conjunto de estudos de validade relativa ao critério no domínio da personalidade relaciona-se com os designados testes de integridade, que avaliam comportamentos contra-produtivos, como o roubo ou absentismo, e comportamentos que estão na génese de problemas disciplinares. Segundo Ones, Viswesvaran e Schmidt (1993) estes testes medem primacialmente o factor conscienciosidade e também os factores de amabilidade e estabilidade emocional. Os estudos de validade preditiva realizados com amostras de candidatos têm demonstrado que o coeficiente de validade obtido com este tipo de testes para o critério desempenho profissional assume valores em torno de 40 . Porém, a magnitude reduzida dos coeficientes de validade não corrigidos e a distorção das respostas resultante da aplicação dos questionários auto-descritivos têm-se constituído como verdadeiros tónicos para o recente debate em torno da problemática da utilização das medidas de personalidade em contextos de selecção (Morgeson, Campion, Dipboye, Murphy, \& Schmidt, 2006). 


\subsection{TESTES PRÁTICOS DE FUNÇÃO}

Os testes práticos de função (work sample tests) têm sido utilizados enquanto ferramentas de selecção desde início do século xx (Roth, Bobko, \& MacFarland, 2005; Salgado et al., 2001). Em Portugal, estes testes práticos de função possuem uma utilização extremamente reduzida (Correia, 2002).

Não obstante tal facto, a evidência empírica coloca estes métodos de selecção, cuja importância é reconhecida por teóricos e práticos, entre os preditores mais robustos do desempenho laboral (Hunter \& Hunter, 1984; Reilly \& Warech, 1993).

Segundo Ployhart, Schneider e Schmidt (2006) uma work sample consiste num teste no âmbito do qual um candidato executa uma série de tarefas que são física e ou psicologicamente similares com as tarefas nucleares da função à qual concerne o teste. Os procedimentos implicados na aplicação deste tipo de testes encontram-se estandardizados e os sistemas de cotação são efectuados por peritos na função em causa (chefias ou colaboradores experientes).

Estes testes baseiam-se na premissa de que o comportamento exibido se constitui no melhor preditor do comportamento futuro (Cook, 2004).

Guion (1998) enfatiza a este respeito que uma das características idiossincráticas de uma work sample relaciona-se com seu elevado grau de fidelidade ou, por outros termos, de baixa abstracção que se verifica entre a mesma e a função à qual diz respeito.

As work samples provocam menos diferenças de pontuação entre grupos étnicos distintos (Cascio, 2003; Schmidt \& Mills, 2001), menor impacto adverso (Callinan \& Robertson, 2000) e reacções mais positivas por parte dos candidatos (Hatrupp \& Schmidt, 1990; Hausknecht, Day, \& Thomas, 2004) do que outros preditores válidos do desempenho profissional, como a aptidão cognitiva geral. No entanto, a investigação que se dedica a averiguar o que é efectivamente medido numa work sample é parca e relativamente embrionária (Cook, 2004; Salgado et al., 2001).

O entendimento actual relativo à validade das work samples deve-se, em grande parte, ao trabalho de Hunter e Hunter (1984). Estes autores reanalisaram os dados de um proeminente trabalho de revisão efectuado por Asher 
e Sciarrino (1974). Esta meta-análise demonstrou que o coeficiente de validade na predição das escalas de avaliação de desempenho situava-se no valor de .54, após correcção do mesmo para a falta de fiabilidade do critério. Este estudo permitiu ainda concluir que no caso dos trabalhadores experientes a validade das work samples revelava-se superior à validade respeitante aos testes de aptidão cognitiva, cujo coeficiente obtido foi de. 51.

Assim, as work samples passaram a ser percepcionadas entre os profissionais como um dos preditores do desempenho profissional com maior validade.

No entanto, Hunter (1983) numa meta-análise anterior e de amplitude mais reduzida que envolveu estudos conduzidos em contextos não-militares, obteve um coeficiente de validade preditiva para as work samples de .42 em relação ao critério desempenho profissional.

Um outro estudo de particular relevo foi conduzido por Schmidt et al. (1984), no qual se averiguou a validade das work samples num conjunto de critérios distintos. Estes autores reportaram coeficientes de validade preditiva não corrigidos das work samples de .32 para as escalas de avaliação de desempenho e de .44 para o critério dimensão relacionada com os salários auferidos pelos colaboradores. O trabalho de Schmidt et al. (1984) foi actualizado por Russel e Dean (1994, cit in Roth et al., 2005) que, através das suas investigações, obtiveram um coeficiente não corrigido de .37 quando o critério considerado respeitou ao desempenho profissional.

Roth, Bobko e MacFarland (2005), num estudo de meta-análise mais recente, obtiveram um coeficiente não corrigido de .26 para as work samples em relação às escalas de desempenho, valor que aumentou para 33 devido às correcções efectuadas para a falta de fiabilidade do critério.

Como podemos verificar, a magnitude deste coeficiente de validade é substancialmente inferior ao coeficiente encontrado por Hunter e Hunter (1984), o que conduziu os autores a sustentarem que a magnitude dos coeficientes de validade das work samples poderá não se revestir de um carácter tão elevado quanto os estudos anteriores postulavam. Os autores defendem que a ausência de estudos de meta-análise nas últimas duas décadas e os problemas metodológicos que podem ter afectado os primeiros trabalhos constituem factores que podem ter induzido os investigadores a pressuporem que a validade das work samples seria superior ao que efectivamente é. 
Um dos aspectos metodológicos que pode ter afectado de forma negativa os primeiros estudos refere-se ao facto da revisão de Asher e Sciarrino (1974) englobar diferentes tipos de testes no rótulo de work samples quando efectivamente não se tratavam de testes que, em rigor, pudessem ser incluídos nesta categoria (como é o caso dos testes de conhecimento de função ou os testes de julgamento situacional).

\subsection{A ENTREVISTA DE SELECÇÃO}

As entrevistas constituem um método amplamente conhecido e com uma utilização transversal aos processos de selecção de pessoas (Salgado et al., 2001).

As entrevistas de selecção consistem numa situação de interacção com o candidato envolvendo uma conversa de índole formal, na qual se avaliam aspectos comportamentais e técnicos. As suas propriedades e características psicométricas podem variar em função do grau de estandardização dos seus procedimentos (estruturação), formato e número de entrevistadores (Peretti, 1998).

Este método, juntamente com a análise curricular, é o que detém uma maior utilização no âmbito da selecção de pessoas em contexto português (Correia, 2002).

Num estudo realizado por Ribeiro (2000), em Portugal, verificou-se que os profissionais que efectuam selecção de pessoas no nosso país percepcionam a entrevista de selecção como o método de maior validade (validade racional, que respeita à percepção subjectiva acerca da validade de um determinado método), atribuindo-lhe grande importância em matéria de selecção.

Um aspecto importante que poderá justificar o recurso generalizado à entrevista enquanto método de selecção relaciona-se com o facto da mesma proporcionar ao avaliador/entrevistador uma situação de face a face com o candidato que potencia a obtenção de um conhecimento mais pormenorizado acerca do mesmo e a dissipação de possíveis dúvidas suscitadas na análise dos aspectos integrantes da sua candidatura.

Um outro factor potencialmente responsável por esta utilização generalizada da entrevista na selecção remete para a sua enorme versatilidade. 
Esta característica inerente à entrevista permite que esta seja utilizada na recolha de informação sobre variáveis de índole diferenciada, podendo incidir sobre conhecimentos, traços de personalidade, estilos de interacção interpessoal, aptidões, valores, interesses e objectivos profissionais dos candidatos (Huffcut, Conway, Roth, \& Stone, 2001).

A investigação sugere que as entrevistas acedem predominantemente a aptidões sociais, experiência profissional e a conhecimentos específicos de função (Robertson \& Smith, 2001).

$\mathrm{Na}$ maior parte dos casos a entrevista influencia de forma determinante o processo de tomada de decisão acerca da selecção dos candidatos, possibilitando acrescentar outros aspectos às informações recolhidas nas fases anteriores de análise curricular, aplicação de questionários, testes psicológicos e/ou testes práticos de função, provas de grupo, entre outros (Newell, 2005).

Com frequência, os profissionais de selecção recorrem à entrevista com o intuito de diagnosticar, em termos subjectivos, a "adequabilidade do candidato" à organização, numa palavra, o seu grau de ajustamento aos valores e à cultura da mesma (Newell, 2005).

Não obstante a sua ampla utilização e notoriedade, diversas críticas têm surgido relativamente à sua utilização para fins de selecção, em particular no caso das entrevistas não estruturadas (MacDaniel, Whetzel, Schmidt, \& Maurier, 1994; Robertson \& Smith, 2001). A sua elevada subjectividade, os enviesamentos de avaliação causados pelo entrevistador e os índices débeis de fidelidade e validade preditiva das entrevistas têm estado na génese de parte substancial destes múltiplos pareceres desfavoráveis (Newell, 2005; Cook, 2004). Estes aspectos conduziram a que algumas organizações se consciencializassem a propósito das limitações deste método, passando a complementá-lo com outros métodos de selecção e a dotarem-no de maior estruturação (Chapman \& Zweing, 2005).

Podemos distinguir três principais tipos de entrevista: as entrevistas estruturadas, as entrevistas semi-estruturadas e as entrevistas não estruturadas.

Nas entrevistas estruturadas o entrevistador segue um procedimento estandardizado no âmbito do qual os candidatos respondem às mesmas questões, segundo uma ordem sistemática e as suas respostas são cotadas com base em escalas de desempenho validadas pelos supervisores e ou 
titulares da função (Campion, Palmer, \& Campion, 1997). As questões que integram estas entrevistas são concebidas com base na técnica dos incidentes críticos que consiste na identificação de comportamentos passíveis de distinguir um bom desempenho de um desempenho medíocre (Anderson \& Shackleton, 1993; Ribeiro, 2000).

Entre as entrevistas estruturadas mais conhecidas encontram-se as entrevistas situacionais e as entrevistas comportamentais (Ribeiro, 2000). $\mathrm{O}$ aspecto que diferencia estes dois tipos de entrevistas radica no referencial temporal das questões que as integram.

As questões das entrevistas comportamentais focam-se no comportamento exibido no passado pelo sujeito em contextos profissionais (ex: recorde-me uma situação em que teve de lidar com uma situação de conflito com um colega de trabalho). Esta referência ao passado profissional conduz a que esta tipologia de entrevista não se revele igualmente proveitosa na avaliação de candidatos que não possuem experiência profissional (Cook, 2004; Janz, 1982).

As entrevistas situacionais, pelo contrário, integram questões que visam verificar os comportamentos que o candidato efectuaria em situações futuras hipotéticas de trabalho com uma determinada relação com a função em causa (Ex: como procederia se tivesse que trabalhar em equipa com um membro que oferecesse resistência a colaborar com o grupo de trabalho) (Latham \& Skarlicki, 1995). As questões que integram este tipo de entrevista têm por objectivo identificar as intenções do candidato no que concerne aos comportamentos de trabalho, partindo-se da premissa que existe uma relação entre intenção e comportamento exibido (Taylor \& Small, 2002). Estas entrevistas apelam de forma mais assinalável às aptidões, na medida em que se focam no comportamento futuro, contrariamente às comportamentais, que reflectem a forma como as pessoas têm desempenhado as funções, permitindo explorar assim variáveis de natureza personalística (Taylor \& Small, 2002).

A entrevista convencional ou psicológica ${ }^{11}$ constitui uma tipologia adicional que envolve uma situação de interacção num registo semi-estruturado entre um entrevistador, geralmente um psicólogo, e o candidato, tendendo

\footnotetext{
11 Não obstante a definição de tipologias de entrevista facilitar o estudo e a clarificação dos seus conteúdos de avaliação, devemos alertar para o facto de grande parte das entrevistas de selecção englobarem um multiplicidade de aspectos e questões pertencentes aos diversos
} 
a incidir de forma mais assinalável em constructos de natureza disposicional, como a personalidade ou o estilo de interacção social (Câmara et al., 2001).

As entrevistas não estruturadas, por sua vez, caracterizam-se por uma grande autonomia e uma ausência de qualquer procedimento previamente estabelecido (Latham \& Finnegam, 1993).

Por vezes, o livre arbítrio conferido ao entrevistador poderá levar a que o mesmo não explore os mesmos aspectos em todos os candidatos inviabilizando que o processo de comparação posterior se concretize de forma fiável (Posthuma, Morgeson, \& Campion, 2002; Newell, 2005). Além do mais, a realização de entrevistas não estruturadas ocorre, por diversas vezes, sem a análise da descrição e a revisão das características individuais passíveis de influenciar o desempenho do sujeito e sem a atribuição de pontuações quantitativas que objectivam o parecer do entrevistador.

Por outro lado, as entrevistas não estruturadas são mais vulneráveis a enviesamentos do entrevistador relacionados com o sexo, grupo de pertença, aspecto físico do candidato, e outras características irrelevantes para a função, mas com grande impacto na avaliação do entrevistador, interferindo com a forma com o mesmo conduz a situação de entrevista (Posthuma, Morgeson, \& Campion, 2002).

Apesar das inúmeras limitações inerentes à entrevista não estruturada, é importante notar que esta permite maior liberdade ao candidato e ao entrevistador para abordarem questões relacionadas com as necessidades, valores, interesses e objectivos mútuos, conduzindo a uma clarificação das expectativas do candidato e a uma clarificação do contrato psicológico (Dipboye, 1994). O autor citado sustenta, a este respeito, que a utilização da entrevista num registo menos estruturado se poderá constituir num facilitador ao estabelecimento do primeiro passo de socialização do candidato, quando lhe é permitido aprender sobre os valores e a cultura da organização.

Por vezes, o grau de estruturação da entrevista decorre da profundidade do conhecimento existente/disponível acerca da função e do seu desempenho. Assim, nas situações nas quais a informação sobre

tipos que impossibilitam que as mesmas sejam incluídas numa determinada categoria (comportamental, situacional ou psicológica). 
os critérios de sucesso da função é difícil de operacionalizar ou a organização se encontra num processo de mudanças funcionais, ou quando a função em causa é altamente influenciada pela envolvente, um registo menos estruturado poderá reunir vantagens (Dipboye, 1997). Nestas condições, a não estruturação da entrevista poderá facilitar a exequibilidade do diagnóstico do ajustamento do candidato à função e à organização (Newell, 2005).

Contudo, a investigação tem demonstrado que a estruturação das entrevistas introduz um factor de controlo susceptível de atenuar alguns das desvantagens mencionadas, constituindo uma questão de considerável importância na melhoria da validade preditiva da entrevista em relação ao critério desempenho profissional (Chapman \& Zweing, 2005; MacDaniel et al., 1994; Wiesner \& Cronshaw, 1988).

Existem outros aspectos, além da estruturação da entrevista, que conduzem a melhorias nas características psicométricas deste método de selecção. O treino dos entrevistadores ${ }^{12}$ (alertando-os para os aspectos relacionados com a distorção ou falsificação das respostas pelos candidatos) e a preparação prévia das entrevistas (ancorando as questões a aspectos relacionados com a função) constituem outros factores importantes no aumento da fidelidade das mesmas (Conway, Jako, \& Goodman, 1995; Cook, 2004).

A investigação tem permitido concluir, a este respeito, que os entrevistadores tendem a hipervalorizar informações que percepcionam como negativas, comparativamente a informações de teor mais favorável, tomando decisões relativas à aceitação ou eliminação do candidato numa fase ainda incipiente da entrevista (Conway et al., 1995; Cook, 2004).

No entanto, a utilização de mais do que um entrevistador diminui a probabilidade da entrevista ser afectada por estes enviesamentos subjectivos que decorrem de aspectos idiossincráticos do candidato (Wiesner \& Cronshaw, 1988), sendo que a utilização dos mesmos entrevistadores durante todo o

12 A preparação dos entrevistadores relaciona-se com a sua capacidade de confrontarem os candidatos com questões relevantes e críticas ao desempenho na função e de estarem mais sensibilizados para os enviesamentos de avaliação que podem ocorrer (Cook, 2004). 
processo de selecção permite que se aumente a validade da entrevista (Conway, et al., 1995; Huffcut \& Woher, 1999).

Por outro lado, a preparação e construção das entrevistas com base na descrição e análise de funções permite que as entrevistas sejam ancoradas em aspectos intrínsecos à função o que conduz a aumentos na sua validade e melhora as suas qualidades psicométricas.

Estes diversos aspectos sucintamente expostos constituem alguns dos contributos da investigação que se tem dedicado ao estudo da validade preditiva das entrevistas de selecção.

Dunnette (1972) realizou o primeiro estudo de meta-análise sobre a validade das entrevistas, recorrendo a 30 estudos primários realizados na industria petrolífera americana e obteve um coeficiente validade de magnitude reduzida de .13 em relação ao critério desempenho profissional. Este coeficiente assume grande similaridade com o coeficiente obtido por Hunter e Hunter (1984) que tomou o valor de .11.

No entanto, outros estudos de meta-análise subsequentes conduziram a resultados mais promissores particularmente no que respeita às entrevistas estruturadas.

Weisner e Cronshaw (1988) conduziram uma meta-análise com estudos realizados na Alemanha, França, Israel e EUA e verificaram um coeficiente médio de .26, sendo que as entrevistas estruturadas atingem valores de .34, enquanto que as não estruturadas ficam pelo valor de .17. A correcção dos coeficientes conduziu a valores de .31 para as entrevistas não estruturadas e de .62 para as entrevistas munidas de um registo estruturado.

A este propósito, MacDaniel, Whetzel Schmidt e Maurer (1994) realizaram um dos estudos mais compreensivos e abrangentes, baseando-se em 245 coeficientes provenientes de estudos primários, o que totalizou uma amostra de 86000 indivíduos. O coeficiente médio corrigido (para a não fiabilidade do critério e restrição de amplitude) obtido para as entrevistas, independentemente da sua estruturação, foi de .20 para o critério desempenho profissional e de .23 para o êxito na formação. No caso das entrevistas estruturadas, os coeficientes assumiram o valor de .24 (.44 após correcção) e de .18 (coeficiente corrigido de .37), no caso das não estruturadas. 
Por seu turno, no mesmo ano, Huffcutt e Arthur (1994) conduziram um estudo de meta-análise que permitiu concluir que os coeficientes das entrevistas não estruturadas atingiam valores de .11 e as estruturadas de .34, utilizando como critério o desempenho.

Posteriormente, Salgado (1999) conduziu uma importante revisão da investigação relacionada com estes aspectos, verificando-se que as entrevistas altamente estruturadas atingem coeficientes corrigidos elevados com o valor de 56 , contrastando com a magnitude reduzida dos coeficientes das entrevistas com menor estruturação, que rondam .20. Esta revisão explicitou também que as questões de entrevista que se baseiam no passado possuem maior validade relativamente às questões que se referem ao futuro (.51 e .39 , respectivamente).

Como podemos verificar, as características psicométricas das entrevistas de selecção oscilam em função de múltiplos factores inerentes, quer ao formato, quer aos entrevistadores. A consciência das limitações da entrevista de selecção, bem como o conhecimento das formas que nos permitem aumentar a sua validade e fidelidade são fundamentais para que possamos munir a sua utilização de maior rigor e eficácia.

\section{Em síntese:}

Após realizarmos a descrição de alguns aspectos importantes em torno da validade preditiva de alguns métodos de selecção atente-se às seguintes notas síntese:

- Os métodos de selecção distinguem-se em termos da sua validade preditiva no critério desempenho profissional individual;

- Múltiplos estudos primários de validação, bem como de meta-análise tem permitido concluir que a aptidão cognitiva geral constitui o melhor preditor do desempenho individual nas diversas funções estudadas. A sua validade generaliza-se a diversos contextos funcionais e organizacionais, concepções de desempenho, culturas e sistemas económicos; 
- A complexidade das funções assume-se como um moderador da validade do factor $g$, sendo que a funções mais complexas (como as funções de gestão) correspondem coeficientes que podem atingir .60 comparativamente a coeficientes à volta de .20 para funções de menor complexidade (ex: funções de produção);

- Apesar dos bons indicadores de validade das medidas de factor g, estas estão também na origem de diferenças significativas entre grupos sociais podendo conduzir a problemas graves relacionados com as resultantes taxas de contratação desiguais entre grupos sociais;

- As aptidões específicas, contrariamente ao que seria expectável, não explicam variabilidade adicional àquela que é imputável ao factor g no critério de desempenho profissional;

- No entanto a investigação no domínio das aptidões especificas detém um carácter mais reduzido para além de ter sido conduzida, na maior parte dos casos, num número mais restrito de funções, recorrendo-se a amostras inferiores comparativamente às que são utilizadas nos estudos de validação do factor g;

- No que respeita aos questionários de personalidade, a emergência da taxonomia big five e a utilização de metodologias de meta-análise em estudos realizados durante a década de 90 permitiram que a investigação neste domínio se revestisse de maior rigor;

- Os estudos de meta-análise permitiram concluir que as variáveis de personalidade constituem preditores válidos do desempenho profissional, contrariamente ao que se postulava nas décadas de 70 e 60;

- Uma quantidade assinalável de estudos tem fornecido suporte à validade do factor conscienciosidade em diversas funções e contextos organizacionais, obtendo-se coeficientes que se situam à volta de .20; 
- A investigação mais recente têm-se debruçado sobre a análise da validade das facetas mais restritas que se agrupam nos factores de personalidade, com o objectivo de verificar se estas variáveis mais específicas constituem preditores mais robustos do desempenho por comparação aos grandes cinco factores;

- A entrevista constitui o método mais utilizado na selecção de pessoas. A sua versatilidade e a possibilidade que a mesma proporciona na dissipação das dúvidas acerca da candidatura dos candidatos através de uma situação de face a face são factores que ajudam a explicar a sua utilização intensiva;

- A estruturação da entrevista, o treino do entrevistador, a sua construção com base em aspectos relacionados com a função e com critérios diferenciadores de desempenho, e a utilização simultânea de mais do que um entrevistador, são factores que incrementam as qualidades psicométricas deste método.

\section{CONCLUSÃo}

Ao longo deste capítulo tratámos de questões claramente polarizadas nos aspectos que se prendem com os conceitos de exactidão e a sua articulação com as características psicométricas dos métodos de selecção. A especificidade e relevância destes aspectos e a extensa literatura produzida acerca desta problemática constituem fortes argumentos que determinaram a dedicação deste capítulo a esta temática. O contraste entre a sua notoriedade nos EUA e em diversos países europeus e a ausência de investigação ou produção científica em contexto português constitui um factor de peso que nos incentivou a produzir este capítulo.

Começámos, então, por apresentar algumas notas fundamentais acerca dos conceitos de fidelidade e validade bem como das formas a partir das quais poderemos reunir evidência acerca da fidelidade e validade de uma determinada medida. Acabamos por dotar de maior relevo as questões 
relacionadas com a validade preditiva de forma a introduzir algumas conclusões importantes de alguns estudos de referência que se incluem neste domínio.

Na secção subsequente detivemo-nos na apresentação e descrição conceptual da variável critério mais utilizada na investigação da validade preditiva dos métodos de selecção: o desempenho profissional individual. Partilhámos o entendimento de que o desempenho profissional individual remete para um conjunto de comportamentos relevantes para a concretização dos objectivos da função e da organização (Astin, 1964 cit in Viswesvaran, 2001).

Apoiando-nos nesta definição avançámos, seguidamente, para a descrição do mesmo enquanto um fenómeno dotado de uma grande complexidade devido à sua natureza abstracta e multidimensional o que justifica, por si só, as dificuldades que emergem na sua medição rigorosa. Concluímos esta secção com uma apresentação das orientações e concepções presentes na literatura acerca das dimensões de desempenho individual (tarefa, contextual e comportamentos contraprodutivos) e das suas implicações na validação dos métodos de selecção.

O capítulo atinge o seu término com a descrição, sob o prisma da validade preditiva, de alguns métodos de selecção: os testes de aptidões cognitivas, os questionários de personalidade, as work samples e as entrevistas de selecção. A discussão destes aspectos faz-se acompanhar da revisão de alguns dos estudos de maior proeminência que percorrem a literatura científica deste domínio.

\section{BIBLIOGRAFIA}

Aguinis, H., Henle, C., \& Ostroff, C. (2001). Measurement in work and organizational psychology. In N. Anderson, D. S. Ones, H. K. Sinargil, C. Wiswesvaran (Eds.), Handbook of industrial, work and organizational psychology (vol. 1). London/New York: Sage.

Anderson, N. \& Ostroff, C. (1997). Selection as socialization. In N. Anderson \& P. Herriot (Eds.), International Handbook of Selection and Assessement. Chicester: Wiley.

Anderson, N. (2001). Towards a theory of socialization impact: selection as pre-entry socialization. International Journal of Selection and Assessent, 9, 84-91.

Anderson, N., \& Shackleton, V. (1993). Successful selection interviewing. Oxford: Blackwell. 
Arvey, R. D., \& Murphy, K. R. (1998). Performance evaluation in work settings. Annual Review of Psychology, 49, 141-168.

Asher, J. J., \& Sciarrino, J. A. (1974). Realistic work sample tests: a review. Personnel Psychology, 27, 519-533.

Avis, J. M., Kudish, D. K., \& Fortunato, V. J. (2002). Examining the incremental validity and adverse impact of cognitive ability and conscientiousness on job performance. Journal of Business and Psychology, 17, 87-105.

Barrick, M. R., \& Mount, M. K. (1991). The big five personality dimensions and job performance: a meta-analysis. Personnel Psychology, 44, 1-26.

Beardwell, J., \& Wrigth, M. (2004). Recruitment and Selection. In J. Beardwell, M. Wrigth \& T. Claydon (Eds.), Human Resources management: A contemporary approach, London: PrenticeHall.

Bertua, C., Anderson, N., \& Salgado, J. F. (2005). The predictive validity of cognitive tests: A UK meta-analysis. Journal of Occupational and Organizational Psychology, 78, 387-409.

Binning, J. F., \& Barret, G.V. (1989). Validity of personnel decisions: A conceptual analysis of the inferential and evidential base. Journal of Applied Psychology, 74, 478-494.

Borman, W. C., \& Motowidlo, S. J. (1993). Expanding the criterion domain to include aspects of contextual performance. In N. Schmidt, W. C. Borman, \& Associates (Eds.), Personnel selection in organizations. San Francisco, CA: Jossey-Bass Publishers.

Callinan, M., \& Robertson, I. T. (2000). Work sample testing. International Journal of Selection $\mathcal{E}$ Assessment, 8, 509-523.

Câmara, P., Guerra, P., \& Rodrigues, J. (2001). Humanator: Recursos humanos e sucesso organizacional (4th ed.). Lisboa: Dom Quixote.

Campbell, J. P. (1990). Modeling the performance prediction problem in industrial and organizational psychology. In M. Dunnette \& L. M. Hough (Eds.), Handbook of industrial and organizational psychology (vol.1, 2 $2^{\text {nd }}$, pp. 687-731). Palo Alto, CA: Consulting Psychologist Press.

Campion, A. E., Palmer, D. K., \& Campion, J. E. (1997). A review of the structure in the selection interview. Personnel Psychology, 50, 655-702

Cardoso, A. (2001). Recrutamento e selecção de pessoal: Manual prático. Lisboa: Lidel.

Carreta, T. R., \& Ree, M. J. (2000). General and specific cognitive and psychomotor abilities in personnel selection: The prediction of training and job performance. In J. F. Salgado (Ed.), Special issue on: Personnel selection at the beginning of a new millennium: a global and international perspective. International Journal of Selection and Assessment, 8, 227-236.

Cascio, W. (2003). Managing human resources: productivity, quality of work life and profits. MacGraw-Hill: Boston.

Chapman, D. S., \& Zweing, D. I. (2005). Developing a nomological network for interview structure: antecedents and consequences of the structured selection interview. Personnel Psychology, 58, 673-702.

Chatman, J. L. (1991). Matching people and organizations: Selection and socialization in public accounting firms. Administrative Science Quarterly, 21, 433-452.

Conway, J. M. (1999). Distinguish contextual performance from task performance for managerial jobs. Journal of Applied Psychology, 84, 3-13.

Conway, J. M., Jako, R.A., \& Goodman, D.F. (1995). A meta-analysis of interrater and internal consistency reliability of selection interviews. Journal of Applied Psychology, 80, 565-579.

Cook, M. (2004). Personnel Selection: Adding value through people ( $4^{\text {th }}$ ed.). Chicester: Wiley.

Correia, A. G. (2002). As práticas de recrutamento e selecção em Portugal. Revista Portuguesa e Brasileira de Gestão, 1, 42-54. 
Decenzo, D. A., \& Robbins, P. R. (2002). Human resource management (7th ed.). Hoboken: Wiley.

Decker, P., \& Cornelius, E. (1979). A note on recruiting sources and job survival rates. Journal of Applied Psychology, 64, 463-464.

Dilchert, S., Ones, D. S., Davis, R. D., \& Rostow, C. D. (2007). Cognitive ability predicts objectively measured counterproductive work behaviors. Journal of Applied Psychology, 92, 616-627.

Dipboye, R. L. (1994). Structured and unstructured interviews: beyond the job-fit model. In G. Ferris (Ed.), Research in Personnel and Human Resources Management (vol. 12). Greenwich, Connecticut: JAI Press, 79-123.

Dipboye, R. L. (1997). Structured selection interviews: Why do they work? Why are the underutilized? In N. Anderson and P. H. Lodsl, International Handbook of Selection and Assessment. New York: John Wiley \& Sons.

Dudley, N. M, Orvis, K. A., Lebiecki, J. E., \& Cortina, J. M. (2006). A meta-analytic investigation of the conscientiousness in the prediction of job performance: Examining the intercorrelations and the incremental validity of narrow traits. Journal of Applied Psychology, 91, 40-57.

Dunnette, M. D. (1972). Validity study results for jobs relevant to the petroleum refining industry. Washington, DC: American Petroleum Institute.

Fuller, L. \& Smith, C. (1991). Consumers' report: Management by customers in a changing economy. Work, Employment and Society, 5, 1-16.

Ghiselli, E. E. (1966). The validity of occupational aptitude tests. New York: Wiley.

Gottfredson, L. S. (2002). Where and why g matters: Not a mystery. Human Performance, 15, 25-46.

Grossman, R. (2000). Measuring up: appropriate metrics help RH improve its worth. HR Magazine 45(1), 28-35.

Guion, R. M. (1998). Assessment, measurement, and prediction forpersonnel decisions. Mahwah: Erlbaum.

Guion, R. M., \& Gottier, R. F. (1965). Validity of personality measures in personnel selection. Personnel Psychology, 18, 135-164.

Hacker, C. (1997). The cost of poor hiring decisions and how to avoid them. HR Focus, 74 (10), 13-24.

Hartigan, J. A., \& Wigdor, A. K. (1989). Fairness in employment testing: Validity generalization minority and the general aptitude test battery. Washington, DC: National Research Council.

Hattrup, K., \& Schmidt, N. (1990). Prediction of trade apprentices' performance on job sample criteria. Personnel Psychology, 43, 453-466.

Hattrup, K., O'Connel, M. S. (1998). Prediction of multidimensional criteria: Distinguish task from contextual performance. Human Performance, 11(4), 305-319.

Hausknchet, J. P., Day, D. V., \& Thomas, S. C. (2004). Applicant reactions to selection procedures: An updated model and meta-analysis. Personnel Psychology, 57, 639-683.

Herriot, P. (1993). Selection as a social process. In M. Smith \& I. T. Roberston (Eds.), Advances in selection and assessment. London: Wiley.

Holton, E. \&, Russell, C. (1999). Organizational entry and exit: An exploratory longitudinal analysis of early careers. Human Performance, 12 (3), 311-42.

Hough, J., \& Ones, D. S, (1997). Conscientiousness and integrity at work. Journal of Business and Psychology, 7, 225-236.

Hough, L. M. (1992). The big five personality variables - construct confusion: Description versus prediction. Human Performance, 5, 139-155.

Hough, L. M., \& Ones, D. S. (2001). The structure, measurement, validity, and use of personality variables in industrial, work and organizational psychology. In N. R. Anderson, D. S. Ones, H. K. Sinangil, \& C. Viswesvaran (Eds.). International handbook of work, and organizational psychology (pp. 233-377). Thousand Oaks, CA: Sage. 
Huffcutt A. I., \& Arthur, W. (1994). Hunter and Hunter (1984) revisited: Interview validity for entry-level jobs. Journal of Applied Psychology, 79, 184-190.

Huffcutt, A. I., \& Woher, D. J. (1999). Further analyses of employment interview validity: a quantitative evaluation of interviewer-related structuring methods. Journal of Organizational Behaviour, 20, 549-560.

Huffcutt, A. I., Conway, J. M., Roth, P. L., \& Stone, N. J. (2001). Identification and meta analytic assessment of psychological constructs measured in employment interviews. Journal of Applied Psychology, 86, 897-913.

Hunt, S. T. (1996). Generic work behaviour: An investigation into the dimensions of entry-level, hourly job performance. Personnel Psychology, 49, 51-83.

Hunter, J. E. (1983). A causal analysis of cognitive ability, job knowledge, and job performance and supervisory ratings. In R. Landy, S. Zedeck, J. Clevelland (Eds.), Performance measurement and theory. Hillsdale, NJ: Erlbaum.

Hunter, J. E., \& Hunter, R. E. (1984). Validity and utility of alternative predictors of job performance. Psycological Bulletin, 96, 72-98.

Hunter, J. E., \& Schmidt, F. L. (1990). Methods of meta-analysis: Correcting error and bias in research findings. London: Sage Publications.

Hurtz, G. M., \& Donovan, J. J. (2000) Personality and Job performance: The big five revisited. Journal of Applied Psychology, 85, 869-979.

Janz, T. (1982). Initial comparisons of patterned behavior description interviews versus unstructured interviews. Journal of Applied Psychology, 67, 577-580.

Kraiger, K., \& Aguinis, H. (2001). Training effectiveness: Assessing training needs, motivation and accomplishments. In M. London (Ed.), How people evaluate others in organizations. Lawrence Erlbaum: Mahwah.

Latham, G. P., \& Finnegam, B. J. (1993). Perceived practicality of unstructured, patterned and situational interviews. In H. Schuler, J. Farr, M. Smith (Eds.), Personnel Selection and assessment: individual and organizational perspectives. Hillsdale NJ: Erlbaum.

Latham, G. P., \& Skarlicki, D. P. (1995). Criterion-related validity of the situational and patterned behavior description interviews with organizational citizenship behavior. Human Peformance, 8, 67-80.

Lees, C.D. \& Cordery, J. L. (2000). Job analysis and design. In N. Chmiel (Ed.) Introduction to work and organizational psychology. Oxford: Blackwell.

Legge, K. (1995). HRM: Rhetoric, reality and hidden agendas. In J. Storey (Ed.), Human resource management: A critical text. London: Routledge.

Levine, E. L., Spector, P. E., Menon, P. E., Narayaon, L., \& Cannon-Bowers, J. (1996). Validity generalisation for cognitive, psychomotor, and perceptual tests for craft jobs in the utility industry. Human Performance, 9, 1-22.

Lima, P. L. (1997). Contextos teóricos e psicométricos "OCEAN" ou "iceberg"? Tese de doutoramento não publicada, Faculdade de Psicologia e Ciências da Educação da Universidade de Coimbra.

MacDaniel, M. A., Whetzel, D. L., Schmidt, F. L., \& Maurer, S. (1994). The validity of employment interviews: a comprehensive review and meta-analysis. Journal of Applied Psychology, 79, 599-616.

Morgenson,F. P., Campion,M.A., Dipboye, R.L., Hollenbeck, J.R.,Murphy, K., \& Schmidtt, N.(2006). Are we getting fooled again? Coming with to terms with limitations in the use of personality tests for personnel selection. Personnel psychology, 60, 1029-1049. 
Morgeson, F. P., Reider, M. H., \& Campion, M. A. (2005). Selecting individuals in team settings: The importance of social skills, personality characteristics and team work knowledge. Personnel Psychology, 58, 583-611.

Motowidlo, S. J., \& Van Scotter, J. R. (1994). Evidence that task performance should be distinguished from contextual performance. Journal of Applied Psychology, 79, 475-480.

Motowidlo, S. J., Borman, W. C., \& Van Scotter, J. R. (1997). A theory of individual differences in task and contextual performance. Human Performance, 10, 71-83.

Mount, M. K., \& Barrick, M. R. (1995). The big five personality dimensions: Implications for research and practice in human resource management. Research in Personnel and Human Resource Management, 13, 153-200.

Mount, M., Ilies, R. \& Jonhson, E. (2006). Relationship of personality traits and counterproductive work behaviors: The mediating effects of job satisfaction. Personnel Psychology, 59, 591-622.

Mount. K. M., Barrick, M. R. (1998). Five reasons why the "Big Five" article has been frequently cited. Personnel Psychology, 51, 849-847.

Mount. K. M., Barrick, M. R., \& Stewart, G. L. (1998). Five factor model of personality and performance in jobs involving interpersonal interactions. Human Performance, 11, 145-165.

Murphy, K. R., \& Shiarella, A. H. (1997). Implications of the multidimensional nature of job performance for the validity of selection tests: multivariate frameworks for studying test validity. Personnel Psychology, 50(4), 823-854.

Murphy, N. (2003). Making every penny count. IRS Employment Review, 789, 42-7.

Newell, S. (2005). Recruitment and selection. In S., Bach (Ed.), Managing Human Resources: Personnel Management in transition. London: Blackwell Publishing.

Nunnally, J. (1978). Psychometric theory. New York: Mc Graw-Hill.

Olea, M. M., \& Ree, M. J. (1994). Predicting pilot and navigator criteria: Not much more than $g$. Journal of Applied Psychology, 79, 845-851.

Olleros, M. (2001). El processo de captación de personal (2nd ed.). Barcelona: Ediciones Gestion 2000 .

Ones, D. Z., Viswesvaran, C., \& Schmidt, F. L. (1993). Comprehensive meta-analysis of integrity validity tests: Findings and implications for personnel selection and theories of job performance. Journal of Applied Psychology, 78, 609-626.

Outtz, J. L. (2002). The role of cognitive ability tests in employment selection. Human Performance, 15, 161-171.

Patterson, M., West, M., Lawthorn, R., \& Nickell, G. (1997). Impact of people management practices on business performance. London: IPD.

Paunonen, S. V. (1998). Hierarchical organization of personality and prediction of behaviour. Journal of Personality and Social Psychology, 81, 524-539.

Pearlman, K., Schmidt, F. L., \& Hunter, J. E. (1980). Validity generalisation results for tests used to predict job proficiency and training success in clerical occupations. Journal of Applied Psychology, 65, 373-406.

Posthuma, R. A., Morgenson, F. P., \& Campion, M.A. (2002). Beyond employment interview validity: a comprehensive narrative interview of recent research and trends over time. Personnel Psychology, 55(1), 851-881.

Rebelo, T. M. (2006). Orientação cultural para a aprendizagem nas organizações: condicionantes e consequentes. Tese de doutoramento não publicada, Faculdade de Psicologia e de Ciências da Educação da Universidade de Coimbra. 
Ree, M. J., Carreta, T. R., \& Steindl, J. R. (2001). Cognitive Ability. In N. Anderson, D. S. Ones, H. K. Sinargil, C. Viswesvaran (Eds.), Handbook of Industrial, Work and Organizational Psychology (vol. 1). London/New York: Sage.

Reeve, C. L., \& Hakel, M. D. (2002). Asking the right questions about g. Human Performance, 15, 47-74.

Reilly, R. R., \& Warech, M.A. (2005). The validity and fairness of alternatives to cognitive ability tests. In L. Wing, B. Gifford (Eds.), Policy issues in employment testing. Boston: Kluwer.

Ribeiro, R. B. (2001). Recrutamento e selecção. In A. Caetano e J. Vala (Eds.), Gestão de recursos humanos: Contextos, processos e técnicas. Lisboa: Editora RH.

Roberts, B. W., Chernyshenko, O. S., Stark, S., \& Goldberg, L. R. (2005). The structure of conscientiousness: An empirical investigation based on seven major questionnaires. Personnel Psychology, 58, 103-139.

Robertson, I. T., \& Kinder, A. (1993). Personality and job competences: The criterion-related validity of some personality variables. Journal of Occupational and Organizational Psychology, 66, 225-244.

Robertson, T. R., \& Smith, M. (2001). Personnel selection. Journal of Occupational and Organizational Psychology, 74, 441-472.

Roth, P. L., Bobko, P., \& Mcfarland, A. M. (2005). A meta-analysis of work sample test validity: updating and integrating some classic literature. Journal of Personnel Psychology, 58 (4), 1009-1037.

Salgado, F. J. (1997) The five factor model of personality and job performance in the European community. Journal of Applied Psychology, 82(1), 30-43.

Salgado, F. J. (2003). Predicting job performance using FFM and non-FFM personality measures. Journal of Occupational and Organizational Psychology, 76, 323-346.

Salgado, J. F., \& Anderson, N. (2002) Cognitive GMA testing in the European community: Issues and evidence. Human Performance, 15, 75-96.

Salgado, J. F., Anderson, N., Moscoso, S., Bertua, C., \& Fruyt, F. (2003). International validity generalization of GMA and cognitive abilities: A European community meta-analysis. Personnel Psychology, 56(3), 573-605.

Salgado, J.F., Viswesvaran, C., \& Ones, D.C. (2001). Predictors used for personnel selection: An overview of constructs, methods and techniques. In N. Anderson, D. S. Ones, H. K. Sinargil, C. Viswesvaran (Eds.), Handbook of industrial, work and organizational psychology (vol. 1). London: Sage.

Salgado, Jesus F. (1999): Personnel selection methods. In C. L. Cooper \& I. T. Robertson (eds.), International Review of Industrial and Organizational Psychology (vol. 14). Chichester: Wiley.

Schmidt, F. L. (2002). The role of general cognitive ability and job performance: why there cannot be a debate. Human Performance, 15 (1/2), 187-210.

Schmidt, F. L., \& Hunter, J. L. (1998). The validity and utility of selection methods in personnel psychology: Practical and theoretical implications of 85 years of research findings. Psychological Bulletin, 124(2), 262-274.

Schmidt, N. \& Mills, A. E. (2001). Traditional test and simulations: Minority and majority performance and tests validities. Journal of Applied Psychology, 86, 451-458.

Schmidt, N., Gooding, R. Z., Noe, R.A., \& Kirsh, M. (1984). Meta-analysis studies published between 1964 and 1982 and the investigation of study characteristics. Personnel Psychology, 37, 407-422.

Schuler, H. (1993). Social valididy of selection situations: a concept and some empirical evidence. In H. Schuler, J. Farr \&, M. Smith (eds.), Personnel Selection and Assessment (4th ed.), New Jersey: Laurence Erlbaum. 


\section{DA EXACTIDÃO DAS MEDIDAS À EFICÁCIA DO PROCESSO DE SELECÇÃO}

Schuler, H., Farr, J., Smith, M. (1993). The Individual and organizational sides of personnel selection and assessmen. In H. Schuler, J. Farr \&, M. Smith (eds.), Personnel Selection and Assessment ( $4^{\text {th }}$ ed.). New Jersey: Laurence Erlbaum.

Shuler, R. S., \& Jackson, S.E. (1996). Human resources management: Positioning for the $21^{\text {st }}$ century. ( $6^{\text {th }}$ ed.)., St Paul, Minnesota: West Publishing Company.

Sisson, K. (1993). In search of HRM. British Journal of Industrial Relations, 31(2), 201-210.

Sisson,K. \& Margison, P. (1995). Management: systems, structures and strategy. In P., Edwards, Industrial Relations: Theory and Pratice in Britain. Oxford: Blackwell.

Smith, M. (1994). A theory of the validity of predictors in selection. Journal of Occupational and Organizational Psychology, 67, 13-31.

Stevens, J. (1968). Applied multivariate statistics for the social sciences. Hillsdale: Lawrence Erlbaum. Stone, J. R. (2002). Human Resource Management ( $4^{\text {th }}$ ed.). Milton: Wiley.

Taylor, P. J., \& Small, B. (2002). Asking applicants what they would do versus what they did do: a meta-analytic comparisation of situational and past behavior employment interview questions. Journal of Occupational and Organizational Psychology, 74, 277-294.

Thorndike, L. J. (1949). Personnel Selection: Tests and measurement technique. New Work: Wiley.

Van Iddekinge, C. H., \& Ployart, R. E. (2008). Developments in the criterion-related validation of selection procedures: A critical review and recommendations for practice. Personnel Psychology, 61, 871-925. 